\title{
Histological evaluation of 400 cholecystectomy specimens
}

\author{
Kumar $\mathrm{H}^{1}$, Kini $\mathrm{H}^{2}$,Tiwari $\mathrm{A}^{3}$ \\ ${ }^{1}$ Department of Pathology, Sarojini Naidu Medical College, Agra, India \\ ${ }^{2}$ Department of Pathology, Kasturba Medical College, Mangalore, India \\ ${ }^{3}$ Department of Pathology, Sawai Man Singh Medical College, Jaipur, India
}

\section{Keywords: \\ Gallbladder; \\ Cholecystitis; \\ Cholelithiasis; \\ Pyloric and intestinal \\ metaplasia; \\ Adenocarcinoma; \\ Carcinoma.}

\begin{abstract}
Background: A majority of gallbladder specimens show changes associated with chronic cholecystitis; however few harbour a highly lethal carcinoma. This study was conducted to review the significant histopathological findings encountered in gallbladder specimens received in our laboratory.

Materials and Methods: Four hundred cholecystectomy specimens were studied over a period of five years (May, 2002 to April, 2007) received at department of pathology, Kasturba Medical College, Mangalore, India.

Results: Gallstones and associated diseases were more common in women in the 4 th to 5 th decade as compared to men with M: F ratio of 1:1.33. Maximum number of patients $(28.25 \%)$ being 41 to 50 years old. Histopathologically, the most common diagnosis was chronic cholecystitis (66.75\%), followed by chronic active cholecystitis $(20.25 \%)$, acute cholecystitis $(6 \%)$, gangrenous cholecystitis (2.25\%),xanthogranulomatous cholecystitis $(0.50 \%)$, empyema $(1 \%)$, mucocele $(0.25 \%)$, choledochal cyst $(0.25 \%)$, adenocarcinoma gallbladder $(1.25 \%)$ and normal gallbladders $(1 \%)$.

Conclusion: All lesions were found more frequently in women except chronic active cholecystitis. Gallstones were present in $(80.25 \%)$ cases, and significantly associated with various lesions (P value 0.009). Pigment stones were most common, followed by cholesterol stones and mixed stones. Adequate sectioning is mandatory in all cases to assess epithelial changes arising from cholelithiasis and chronic cholecystitis as it has been known to progress to malignancy in some cases.
\end{abstract}

\section{INTRODUCTION}

Gallbladder is one of the most commonly encountered specimens in the surgical pathology laboratory. A majority

\section{Correspondence:}

Dr. Hema Kini, MBBS, MD

Professor, Department of Pathology

Kastruba Medical College, Manglore, India.

Email:hemakini@hotmail.com of these specimens show rather mundane changes associated with chronic cholecystitis, however minority will harbor a highly lethal carcinoma. Often underappreciated, the gallbladder may be affected by a variety of pathological processes that have specific clinical correlates. Reactive changes within cholecystitis may mimic dysplasia. The number of cholecystectomy has increased more than $50 \%$ in the last decade, a vast majority performed annually 
for gallstone related diseases. Usual stone associated cholecystitis has only mild inflammation, but variants of cholecystitis may have abundant xanthoma cells, eosinophils or lymphocytes and plasma cells. Metaplasia from the normal columnar absorptive epithelium into mucinous epithelium occurs in some cases and few may progress to dysplasia which is thought to be the main precursor of invasive gallbladder carcinoma. Most invasive carcinomas present at advanced stage and therefore are highly lethal. Role of surgical pathologist is to detect these changes \& distinguish between them. Resections of gallbladder performed in such cases must be accurately classified and staged to provide optimal prognostic information. ${ }^{1}$

\section{MATERIALS AND METHODS}

In the present study 400 gallbladders (GB) specimens of South Indian patients were received in department of pathology, Kasturba Medical College, Mangalore (India), were studied over a period of 5 years from May 2002 to April 2007. The study was permitted to conduct by institutional ethical committee. Gallbladder specimens were received in department of pathology from Govt. Wenlock hospital, Kasturba Medical Hospitals, Attavara and Ambedkar circle, and other private hospitals in \& around Mangalore. Detailed history and other investigations were obtained. The specimens were received in $10 \%$ formalin. Prompt fixation of gallbladder was done because the epithelium is quite susceptible to bile- related autolysis. Further grossing was done as per standard protocol. ${ }^{2,3}$ The following sections were given for histology: ${ }^{4}$ Cystic duct, three sections from fundus, body and neck of the gallbladder were given in each of two cassettes. Lymphnode, when present was submitted for histopathology. Additional sections were given from other gross lesions when present e.g. carcinoma. The tissues were processed as per the standard paraffin processing technique. Sections were stained with hematoxylin and eosin (H\&E).

This study was done to study histopathology of gallbladder for evidence of cholecystitis, cholelithiasis, metaplasia, dysplasia and malignancy and to ascertain the presence

Table 1: Sex distribution in different age groups

\begin{tabular}{lcc}
\hline \multicolumn{1}{c}{ Age group } & No. of Men (\%) & No. of women (\%) \\
\hline $0-10 \mathrm{yrs}$ & $02(1.16 \%)$ & 00 \\
$11-20 \mathrm{yrs}$ & $08(4.65 \%)$ & $05(2.19 \%)$ \\
$21-30 \mathrm{yrs}$ & $22(12.79 \%)$ & $39(17.11 \%)$ \\
$31-40 \mathrm{yrs}$ & $19(11.05 \%)$ & $50(21.93 \%)$ \\
$41-50 \mathrm{yrs}$ & $55(31.97 \%$ & $58(25.44 \%)$ \\
$51-60 \mathrm{yrs}$ & $35(20.35 \%)$ & $35(15.35 \%)$ \\
$61-70 \mathrm{yrs}$ & $19(11.05 \%)$ & $24(10.53 \%)$ \\
$71-80 \mathrm{yrs}$ & $08(4.65 \%)$ & $16(7.01 \%)$ \\
$81-90 \mathrm{yrs}$ & $04(2.33 \%)$ & $01(0.44 \%)$
\end{tabular}

of precursors of dysplasia in the gallbladder involved by chronic cholecystitis.

\section{RESULTS}

Four hundred specimens of gallbladder received over a period of five years in our institution were analyzed histopathologically.

\section{Patient characteristics}

Age \& Sex distribution: Out of 400 cases, there were 172 (43\%) men and $228(57 \%)$ women with M: F ratio of 1 : 1.33. The age of the patients varied from $1 \frac{1 / 2}{2}$ years to 85 years, with common mean age of $45.56 \pm 15.48$ yrs. Mean age for men was $47.47 \pm 15.65 y$ rsand for women was 45.87 \pm 15.34 yrs. We found that a majority of patients of both sexes were in the age range of 41-50yrs, with men (31.97\%)

\begin{tabular}{|c|c|c|c|c|}
\hline $\begin{array}{l}\text { S. } \\
\text { No. }\end{array}$ & Diagnosis & No. of cases $(\%)$ & Men & Women \\
\hline 1 & Chronic cholecystitis & $267(66.75 \%)$ & 107 & 160 \\
\hline 2 & Chronic active cholecystitis & $81(20.25 \%)$ & 45 & 36 \\
\hline 3 & Acute cholecystitis & $24(6 \%)$ & 10 & 14 \\
\hline 4 & Gangrenous cholecystitis & $9(2.25 \%)$ & 05 & 04 \\
\hline 5 & Normal gall bladder & $5(1.25 \%)$ & 01 & 04 \\
\hline 6 & Autolysed gall bladder & $1(0.25 \%)$ & 01 & 00 \\
\hline 7 & $\begin{array}{l}\text { Xanthogranulomatous } \\
\text { cholecystitis }\end{array}$ & $2(0.50 \%)$ & 00 & 02 \\
\hline 8 & Empyema & $4(1.00 \%)$ & 02 & 02 \\
\hline 9 & Mucocele & $1(0.25 \%)$ & 00 & 01 \\
\hline 10 & Choledochal cyst & $1(0.25 \%)$ & 01 & 00 \\
\hline 11 & Adenocarcinoma & $5(1.25 \%)$ & 01 & 04 \\
\hline
\end{tabular}

Table 3: Gall bladder diseases and its association with Gall stones

\begin{tabular}{|c|c|c|c|}
\hline & \multicolumn{2}{|c|}{ No. of cases (\%) } & \multirow[b]{2}{*}{ Total } \\
\hline & no stones & with stones & \\
\hline $\begin{array}{c}\text { Acute cholecys- } \\
\text { titis }\end{array}$ & 7 & 17 & 24 \\
\hline Adenocarcinoma & 1 & 4 & 5 \\
\hline $\begin{array}{l}\text { Autolysed gall } \\
\text { bladder }\end{array}$ & 1 & 0 & 1 \\
\hline Choledochal cyst & 1 & 0 & 1 \\
\hline $\begin{array}{l}\text { Chronic active } \\
\text { cholecystitis }\end{array}$ & 23 & 58 & 81 \\
\hline $\begin{array}{l}\text { Chronic chol- } \\
\text { ecystitis }\end{array}$ & 40 & 227 & 267 \\
\hline Empyema & 0 & 4 & 4 \\
\hline $\begin{array}{l}\text { Gangrenous } \\
\text { cholecystitis }\end{array}$ & 4 & 5 & 9 \\
\hline Mucocele & 0 & 1 & 1 \\
\hline $\begin{array}{l}\text { Normal gall } \\
\text { bladder }\end{array}$ & 2 & 3 & 5 \\
\hline $\begin{array}{l}\text { Xanthogranu- } \\
\text { lomatous } \\
\text { cholecystitis }\end{array}$ & 0 & 2 & 2 \\
\hline Total & 79 & 321 & 400 \\
\hline
\end{tabular}


Table 4: Microscopic features observed in gall bladders

\begin{tabular}{|c|c|c|c|}
\hline $\begin{array}{c}\text { S. } \\
\text { No }\end{array}$ & Microscopic feature & No. of cases & Percentage \\
\hline 1 & Normal epithelium & 17 & $4.25 \%$ \\
\hline 2 & Ulceration & 152 & $38 \%$ \\
\hline 3 & Denudation (focal/ diffuse) & 233 & $58.25 \%$ \\
\hline 4 & $\begin{array}{l}\text { Epithelial Hyperplasia- } 126(31.50 \%) \\
\text { - Papillary } \\
\text { - Spongiform } \\
\text { - Combined }\end{array}$ & $\begin{array}{l}76 \\
30 \\
20\end{array}$ & $\begin{array}{c}19 \% \\
7.50 \% \\
5 \%\end{array}$ \\
\hline 5 & $\begin{array}{l}\text { Metaplasia - } 95(23.75 \%) \\
\text { Pyloric type } \\
\text { Intestinal type } \\
\text { Squamous type } \\
\text { Combined (pyloric + intestinal) }\end{array}$ & $\begin{array}{c}79 \\
11 \\
3 \\
2\end{array}$ & $\begin{array}{l}19.75 \% \\
2.75 \% \\
0.75 \% \\
0.50 \%\end{array}$ \\
\hline 6 & Reactive changes & 19 & $4.75 \%$ \\
\hline 7 & Dysplasia (low grade) & 7 & $1.75 \%$ \\
\hline 8 & Fibrosis & 392 & $98 \%$ \\
\hline 9 & Rokitansky - Aschoff sinus & 314 & $78.50 \%$ \\
\hline 10 & Congestion & 372 & $93 \%$ \\
\hline 11 & Hypertrophic nerve bundles (HNB) & 98 & $24.25 \%$ \\
\hline 12 & $\begin{array}{l}\text { Malignancy - total } \\
\text { - Papillary type } \\
\text { - Adenocarcinoma- NOS }\end{array}$ & $\begin{array}{l}5 \\
3 \\
2\end{array}$ & $\begin{array}{l}1.25 \% \\
0.75 \% \\
0.50 \%\end{array}$ \\
\hline
\end{tabular}

predominating over women $(25.44 \%)$. There were 2 pediatric cases and 5 octogenarians (Table 1).

We found that in both men and women the most common age group having cholecystitis and cholelithiasis was 41 $50 \mathrm{yrs}$ (55 men and 58 women), followed by 51-60 yrs in men $(20.35 \%)$ and $31-40$ years in women $(21.93 \%)$. Thus, we found that gallstones \& associated lesions in women were seen at a lower age group than in men.

Out of 400 gallbladders, chronic cholecystitis was the most common diagnosis (table 2) in $267(66.75 \%$ ) cases, affecting more females $(59.93 \%)$ than males $(40.07 \%)$. It was characterized by varying degrees of lymphoplasmacytic, histiocytic and eosinophilic infiltration along with fibrosis of the gallbladder wall, presence of Rokitansky-Aschoff sinuses, hyperplasia, metaplasia and reactive epithelial changes (Table 2).

\section{Gall stones}

In the present study gall stones, either single or multiple, were seen in $80.25 \%$ of cases (Table 3). Gall stones were present in $77.90 \%$ men, and $82 \%$ women. Stones were seen most frequently in chronic cholecystitis in $85 \%$ cases. They were also associated with other conditions such as, $70.80 \%$ cases of acute cholecystitis, $71.6 \%$ cases of chronic active cholecystitis, $55.6 \%$ cases of gangrenous cholecystitis, $100 \%$ cases of empyema gallbladder, $80 \%$ cases of adenocarcinoma, $100 \%$ cases of xanthogranulomatous cholecystitis, $100 \%$ case of mucocele.

In a majority of the cases $(80.50 \%)$ the serosal surface was congested, while the rest $(19.50 \%)$ showed normal serosa. Thickening of the gallbladder wall due to fibrosis, edema and inflammatory infiltrate was seen in $94.25 \%$ specimens, most showing features of chronic cholecystitis.

\section{Inflammation}

Lymphoplasmacytic infiltrate was seen in $72.50 \%$ cases varying from mild to dense. Mixed inflammation was seen in $27.5 \%$ cases. Eosinophils were present in $22.50 \%$ cases. Focal lymphoid aggregates and lymphoid follicles were seen in $5.75 \%$ cases. Foamy histiocytes were seen in $4 \%$ cases. Focal granulomas were seen in $0.75 \%$ cases and multinucleated histiocytic giant cells in $1.50 \%$ cases. Mild to moderate fibrosis was the most consistent finding in 98\%. Rokitansky-Aschoff sinuses were seen in $78.5 \%$ cases of chronic cholecystitis and chronic active cholecystitis. Congestion of the gallbladder wall, especially the subserosal blood vessels, was seen in 93\%. Hypertrophic nerve bundles were seen in $24.25 \%$, associated with obstruction either at the level of cystic duct or common bile duct (table 4).

\section{Hyperplasia}

In $31.50 \%$ cases (table 4), the epithelium showed hyperplastic changes, out of which papillary hyperplasia most common (19\%) was followed by spongiform type $(7.5 \%)$. Combined hyperplasia was seen in 5\% cases. It was more common in females. Hyperplastic changes were seen most commonly in chronic cholecystitis (100 cases), chronic active cholecystitis (22 cases), and acute cholecystitis (4 cases). Only one case showed associated cytological atypia of the epithelium.

\section{Metaplasia}

Metaplastic changes were seen in $23.75 \%$ cases (table 4 ), out of which $19.75 \%$ cases were of pyloric type followed by $2.75 \%$ cases of intestinal type metaplasia. Two cases $(0.50 \%)$ showed both intestinal and pyloric type of metaplasia. Three cases showed focal squamoid differentiation. Pyloric metaplasia was more commonly seen in women (41 cases) than in men (38 cases). Out of 11 cases of intestinal

Table 5: Incidence of hyperplasia, metaplasia, dysplasia and carcinoma

\begin{tabular}{|c|c|c|c|c|c|c|c|c|c|c|c|c|}
\hline Sex & $\begin{array}{c}\text { No. of pt. } \\
(\%)\end{array}$ & $\begin{array}{c}\text { Mean } \\
\text { age }\end{array}$ & & asis & Hyperpl & & & & lasia & & Dysplasia & $\mathrm{CA}$ \\
\hline \multirow{2}{*}{ Women } & \multirow{2}{*}{$228(57 \%)$} & \multirow{2}{*}{$45.87 \mathrm{yrs}$} & No. & $\%$ & No. & $\%$ & Pyloric & Intestinal & Squamous & Combined & \multirow{2}{*}{$5(2.19 \%)$} & \multirow{2}{*}{$4(1.75 \%)$} \\
\hline & & & 187 & $82 \%$ & $82 / 228$ & $35.96 \%$ & $41(17.9 \%)$ & $4(1.7 \%)$ & $2(0.87 \%)$ & $1(0.4 \%)$ & & \\
\hline Men & $172(43 \%)$ & $47.47 \mathrm{yrs}$ & 134 & $77.90 \%$ & $44 / 172$ & $25.58 \%$ & $38(22.09)$ & $7(4.06 \%)$ & $1(0.58)$ & $1(0.58 \%)$ & $2(1.16 \%)$ & $1(0.58 \%)$ \\
\hline
\end{tabular}


Table 6: Clinico-pathological characteristics of five cases of carcinoma gallbladder

\begin{tabular}{ccccccccc}
\hline Sex & No of pt & Mean age & With Lithiasis & Cholecystitis & Dysplasia & \multicolumn{2}{c}{ Histologic type } \\
\cline { 7 - 9 } & & & & & & Papillary type & Adenocarcinoma \\
Women & 4 & $60.75 \mathrm{yrs}$ & 3 & 4 & 3 & 2 & 2 \\
Men & 1 & $42 \mathrm{yrs}$ & 1 & 1 & 1 & 1 & 0
\end{tabular}

metaplasia four were women, and seven were men. Mean age for hyperplasia was $42.62 \mathrm{yrs}$. The mean age for pyloric metaplasia was 49.67 yrs. The mean age for intestinal metaplasia was $42.81 \mathrm{yrs}$, whereas these values were high for dysplastic changes with mean age of 56.43yrs. Three cases showed focal squamoid differentiation. Two cases were females and one was male patient. It was seen in two cases of chronic active cholecystitis and one case of gangrenous cholecystitis. These three cases did not show any associated hyperplasia or dysplasia.

\section{Dysplasia}

It is precursor lesion for gallbladder cancer characterized by abnormally polarized, apically oriented cigar-shaped hyperchromatic nuclei and absence of inflammation. We found dysplasia in seven $(1.75 \%$ ) cases (Table 4). Five were women and two were men. It was seen in four cases of malignancy in the adjacent mucosa, two cases showing features of chronic cholecystitis and one case of acute cholecystitis.

\section{Reactive epithelial changes}

Reactive changes were seen in $4.75 \%$ cases(Table 4 ). The epithelial cells showed enlarged but regular nuclei associated with dense inflammation in the lamina propria. It was seen most commonly in chronic active cholecystitis ( 8 cases) and chronic cholecystitis ( 8 cases). Two cases had associated acute cholecystitis and one gangrenous cholecystitis.

\section{Carcinoma Gallbladder}

Malignancy was seen in $5(1.25 \%)$ of 40 cases (Table 4$)$. Three $(0.75 \%)$ cases were of papillary type (fig. 1$)$ and the other two $(0.50 \%)$ were adenocarcinoma (fig. 2$)$, NOS (table $6)$. Four cases were females. The mean age of malignancy in women was 60.75 yrs. The onlyman was 42 years of age.

Out of five cases of carcinoma, four cases had associated gallstones. All five cases showed associated features of cholecystitis and four cases showed dysplasia in the adjacent mucosa.

\section{DISCUSSION}

Inflammatory diseases of the gallbladder are a frequent cause of morbidity in the West. In India, eastern Uttar Pradesh and Indo Gangetic belt is amongst the highest incidence of gallbladder carcinoma in the world (along with Chile $\&$ Bolivia). The term cholecystitis encompasses a group of disorders that differ in their pathologic, pathogenetic and clinical characteristics. However, characterization of inflammatory patterns helps the pathologist to establish a diagnosis and provides insight into the pathogenesis of a disease. In addition, it is through the recognition of differences in inflammatory patterns that clinically useful histologic diagnoses are rendered. ${ }^{5}$

Specimens with chronic cholecystitis are associated with cholelithiasis in about $95 \%$ of cases. Chronic cholecystitis may follow single or recurrent attacks of acute cholecystitis. Chronic acalculous cholecystitis is much less common. Patients may experience biliary colic presumably due to longstanding irritation by bile with abnormal composition and/or gallbladder dysmotility. There is in general a poor correlation between clinical symptomatology and the number, size or volume of gallstones, suggesting other factors are involved. ${ }^{6}$

\section{Sex distribution}

In our study of 400 cases, M: F ratio of 1:1.33 which was higher than other Indian studies ranging from 1:2.63 to 1:6.4. ${ }^{7-9}$ Acute cholecystitis was diagnosed in more women (14 cases) as compared to men (10 cases). This was in contrast to previous study ${ }^{10}$. Chronic cholecystitis was also more common in women. This was consistent with Adsay1, who reported female preponderance. Chronic active cholecystitis was seen in 45 men and 36 women.

Gallstones were seen in $80.25 \%$ cases, predominantly in women. This observation was also concurrent with previous studies by Mohan el al \& Adsay, who described predominance of gallstones in women. ${ }^{1,8}$ The incidence increases with age, possibly owing to a progressive increase in the secretion of biliary cholestrol.

Adenocarcinoma of the gallbladder was diagnosed in 5 cases $(1.25 \%)$ with female predominance ( 4 cases). This observation concurred with Henson et al who found carcinoma in $73.32 \%$ women. ${ }^{11}$

\section{Age distribution}

The mean age of patients was 45.56 years \pm 15.48 years. Other studies have also shown predominance of women in fourth and fifth decade among patients with stone diseases. ${ }^{7-9}$ 
Sex hormones and sedentary habits of most women in India expose them to factors that possibly promote the formation of gallstone. ${ }^{8}$ The mean age of patients with acute cholecystitis was 51.92 years. Glenn et al reported that it was more frequent in patients older than 65 years of age. ${ }^{10}$

The mean age for chronic cholecystitis and chronic active cholecystitis were 46.24 and 46.84 years, respectively. The mean age for epithelial hyperplasia, pyloric metaplasia, intestinal metaplasia and dysplasia was 42.62 years, 49.67 years, 42.81 years and 56.43 years, respectively. Mukhopadhyay et $\mathrm{al}^{12}$ found the mean age for pyloric metaplasia, intestinal and dysplasia to be 48.4 years, 50.9 years and 52.6 years, respectively. Carcinoma was diagnosed in elderly women (4cases) with the mean age of 60.75 years. Perpetuo 13 reported mean age of 62 years and with female preponderance. Albores- Saavedra et a ${ }^{14}$ studied 42 cases of invasive gallbladder carcinomas and they found that it was more common in women $(88 \%)$, with a mean age of 59 years.

\section{Cholelithiasis}

Gallstones are a major cause of morbidity and mortality throughout the world. They are associated with a variety of lesions including acute cholecystitis, chronic cholecystitis with its variants, and carcinoma gallbladder. Cholelithiasis produces a series of epithelial pathological changes which could be precursor lesions of gallbladder cancer. These changes include hyperplasia, metaplasia and dysplasia. ${ }^{9}$ In present study gallstones were detected in $80.25 \%$ cases. Gallstones were seen in association with in acute cholecystitis $(70.8 \%)$, chronic cholecystitis $(85 \%)$, chronic active cholecystitis (71.6\%), xanthogranulomatous cholecystitis $(100 \%)$ and adenocarcinoma $(80 \%)$. This association (table 3) was statistically highly significant (P value 0.009). Out of 115 cases, pigment stones were predominant ( 83 cases). Cholesterol stones were found in 27 cases and mixed stones in 5 cases. In India, cholelithiasis was found to be seven times more common in North India than in South India, and predominantly affected women (M: $\mathrm{F}=1: 6.4)$. The estimated prevalence of gallstone disease in India has been reported as $2 \%$ to $29 \%{ }^{8}$

\section{Acute Cholecystitis}

It may occur either in the presence of gallstone impaction within the cystic duct or in the setting of chronic debilitation without gallstones, like in acalculous acute cholecystitis. ${ }^{15}$ It was characterized by marked congestion, edema, hemorrhage, acute inflammatory infiltrate and fibroblastic proliferation (fig.3). We found $6 \%$ cases of acute cholecystitis, out of which $70.8 \%$ cases had gallstones (Table 3 ). This was more common in women. Glenn et a ${ }^{10}$ reported $6.17 \%$ acute cholecystitis cases in his study occurring more frequently in males with the majority 65 years and above. Dix et $\mathrm{a}^{15}$ reported $2.9 \%$ cases showing acute cholecystitis or empyema. In our study, acute cholecystitis was seen in older patients (mean age 51.92 years).
Gangrenous cholecystitis occurred in about $2.5 \%$ of all patients coming for surgical exploration at the Mayo Clinic. In $75 \%$ of cases, the symptoms were typical of recurrent acute cholecystitis or chronic cholecystitis. A palpable tender gallbladder was present in $45 \%$ of cases. Extensive necrosis was the typical finding, resembling complete infarction. The pathogenesis of gangrenous cholecystitis was thought to be due to ischemia because of either valvular insufficiency or obstruction with distention of the gallbladder and secondary vascular insufficiency. ${ }^{6}$ In our study it was seen in $2.25 \%$ cases with slight preponderance in men.

Xanthogranulomatous cholecystitis is an unusual variant of chronic cholecystitis has been reported in $1.8 \%$ to $8.9 \%$ of cholecystectomy specimens ${ }^{6}$. In our study, two cases were diagnosed as xanthogranulomatous cholecystitis and both were associated with gallstones.

Empyema gallbladder is an unusual condition characterized by purulent infection of the gallbladder superimposed on obstruction of the cystic duct. The lumen is often distended with pus. Several reviews have identified empyema of the gallbladder in $2 \%$ to $11 \%$ of patients undergoing cholecystectomy. 6 We had 4 cases $(01 \%)$ in this study and all had associated cholelithiasis.

\section{Chronic cholecystitis and chronic active cholecystitis}

Chronic inflammation to some degree is seen in most cases of chronic cholecystitis, and it may vary greatly in severity and distribution. When there is mixed acute and chronic inflammation, the term chronic active cholecystitis has been used. Rokitansky- Aschoff sinuses are a characteristic feature of chronic cholecystitis, occurring in about $90 \%$ of cases. A variety of hyperplastic and metaplastic changes may be present. Hypertrophy of the muscularis may be present with longstanding and /or progressive disease. The wall of the gallbladder may become very fibrotic. ${ }^{6}$

In our study chronic cholecystitis was diagnosed in $66.75 \%$ cases, whereas $20.25 \%$ cases were diagnosed as chronic active cholecystitis (Table 2). Chronic cholecystitis was more common in women, whereas chronic active cholecystitis was slightly more common in men. Eighty five percent cases of chronic cholecystitis had gallstones, whereas $71.6 \%$ of chronic active cholecystitis was associated with cholelithiasis. Gupta et $\mathrm{al}^{17}$ found gallstones in $79 \%$ cases of chronic cholecystitis. We found lymphoplasmacytic infiltrate in $72.5 \%$ cases. Eosinophils were present in $22.5 \%$ cases, as a part of inflammation. Focal lymphoid aggregates were seen in $5.75 \%$ cases. Foamy histiocytes were seen in $4 \%$ cases. Fibrosis of the gallbladder wall was the most consistent finding seen in $98 \%$ of cases. Rokitansky-Aschoff sinuses were seen in $78.5 \%$ of cases (Table 4 ). Hypertrophic nerve bundles were seen in 57 cases of chronic cholecystitis and 30 cases of chronic active cholecystitis. Hypertrophic nerve bundles probably occur secondary to obstruction. 


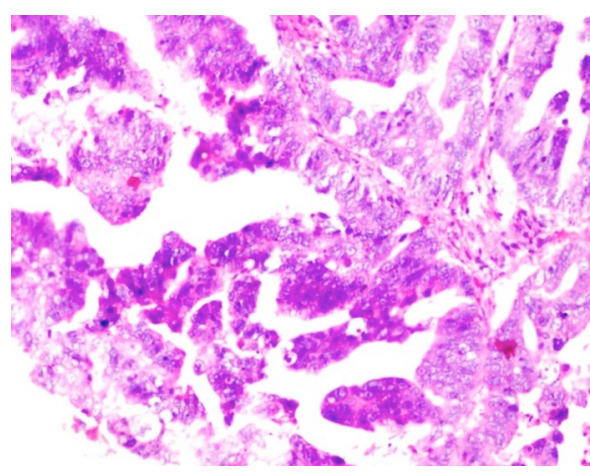

Figure 1: Papillary adenocarcinoma showing prominent papillae with fibrovascular core (HE stain, X400).

\section{Hyperplasia, Metaplasia and Dysplasia}

Chronic cholecystitis and chronic active cholecystitis were associated with various types of hyperplastic and metaplastic changes. Out of 126 (31.50\%) cases showing hyperplasia, 100 cases had chronic cholecystitis and 22 cases were chronic active cholecystitis. Hyperplastic changes (fig. 4) were seen in $35.96 \%$ women as compared to $25.58 \%$ men (Table 5).

Metaplastic changes were seen in $95(23.75 \%)$ cases. Metaplasias of antral and intestinal type (figure 5) are frequently seen in gallbladders containing stones. It was presumed that prolonged irritation by gallstones and / or chronic inflammation led to metaplastic changes of gallbladder mucosa which may occasionally and eventually lead to the development of carcinoma. Khanna et $\mathrm{al}^{9}$ reported $16 \%$ each in their study. We found, pyloric metaplasia in $79(19.75 \%)$ cases, intestinal metaplasia in $11(2.75 \%)$ cases, combined (Pyloric and intestinal) in 2 cases and squamous metaplasia in $3(0.75 \%)$ cases. Dysplasia was seen in $7(1.75 \%)$ cases, it was seen in the adjacent mucosa to carcinoma in five cases and in two cases of chronic cholecystitis (Table 4). We found epithelial changes in less number of cases than Duarte et at ${ }^{18}$ who found pyloric metaplasia in $95 \%$, intestinal metaplasia in $58.1 \%$ hyperplasia in $46.9 \%$ and dysplasia in $16 \%$ of cases. Albores-Saavedra et al ${ }^{14}$ reported hyperplasia in $83 \%$ and atypical hyperplasia in $13.5 \%$ cases. Mukhopadhyay and Landas ${ }^{12}$ found pyloric metaplasia in $59.5 \%$ intestinal metaplasia in $9.8 \%$ and dysplasia in $5 \%$ of cases.

According to Duarte et $\mathrm{al}^{18}$ a single random section might detect less than one third of hyperplasia, dysplasia and carcinomas in-situ occurring in the gallbladder. Thus, emphasizing the importance of studying multiple sections. The malignant potential of these conditions in gallbladder is uncertain but incidence of malignant transformation would progressively increase from hyperplasia to metaplasia to dysplasia to carcinoma in- situ.

\section{Carcinoma}

Gallbladder carcinoma is a rare but fatal disease

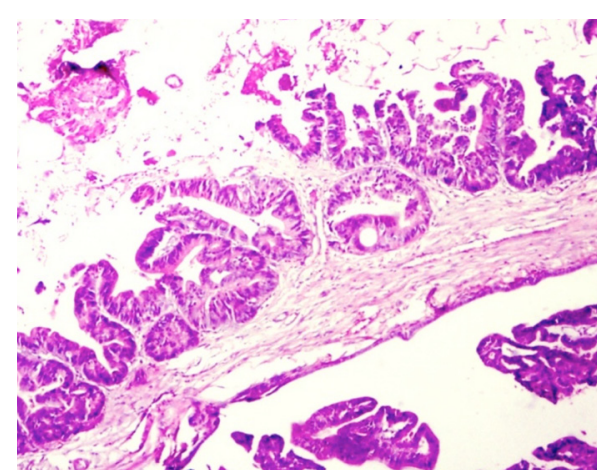

Figure 2: : Invasive adenocarcinoma of the gallbladder (HE stain, X100).

characterized by poor prognosis and absence of effective therapy ${ }^{19}$ carcinoma constitutes 3- $4 \%$ of all malignant lesions ${ }^{17}$ and is the commonest malignancy of the biliary tract. It has a striking geographic and ethnic variation. The reported incidence of carcinoma in India varies from 4.4 to $12.4 \% .{ }^{20}$ It was 10 times more frequent in North India as compared to South India. Gallstones appear to be the most important risk factor, being reported in $70-98 \%$ cases of gallbladder cancer, a far higher prevalence than that in age matched general population. ${ }^{9}$ Despite the strong association between carcinoma and presence of gallstone, the casual relationship between gallstone disease and carcinoma has not been established. Only 1-3\% of patients with gallstones go on to develop carcinoma and many patients without gallstones develop carcinoma. Chronic inflammation and trauma of stones-containing gallbladder may lead to dysplasia, and subsequent progression to carcinoma. The median survival in most cases is less than 6 months; the overall 5 year survival rate is less than $5 \% .{ }^{19}$

The great majority of in-situ carcinomas is grossly indistinguishable from cholecystitis and could easily be overlooked on macroscopic examination. The gallbladder wall may be normal or minimally thickened. The mucosa may appear granular, slightly nodular, plaque- like or trabeculated. Thus, the pathologist may have no definite guide as to where to cut the representative section and the incidence of in- situ carcinoma could be greatly underestimated. ${ }^{9}$

Gallbladder carcinoma has been an uncommon disease in our institution (south Indian population). We found only 5 cases $(1.25 \%)$, out of 400 cases received over a period of five years (Table 2). Malignancy was more common in elderly females with a mean age of $60.75 \mathrm{yrs}$. Gallstones were detected in four cases $(80 \%)$. Three cases were papillary adenocarcinomas (fig. 6) and the remaining two were usual adenocarcinomas of the gallbladder. The signs and symptoms of carcinoma are non-specific, mimicking chronic cholecystitis (pain, anorexia and elevated alkaline phosphatase) and manifest only after the tumor has inflicted substantial damage. ${ }^{1}$ In our cases most common presenting manifestations were jaundice and right hypochondriac pain (5/5 cases). 
Transmural penetration of adenocarcinoma is common and tumor extends into the subserosal or adventitial connective tissue readily due to the thin wall of the gallbladder, may invade the liver and adjacent structures by direct extension. ${ }^{6}$ In two of our cases, the gallbladder had transmural infiltration by tumor (fig.7) and three cases showed infiltration only up to the muscle layer. In one case the specimen was received in fragments. The resected cystic duct margin was involved by tumor in two cases. In two cases, the malignant process caused diffuse thickening gallbladder wall, making it difficult to distinguish from chronic cholecystitis. This observation stressed the importance of microscopic examination of every resected gallbladder. Diffuse infiltration type may create a picture reminiscent of linitisplastica and may spread linearly along the extrahepatic bile ducts as well. Most carcinomas arise in the fundus $(60 \%)$, followed by the body $(30 \%)$. Those in the neck $(10 \%)$ often grow into cystic duct and the precise origin may be difficult to determine. ${ }^{1}$ Of our 5 cases, one arose in the fundus, one in the body and two were diffuse growths. The location of the fifth could not be determined, as the tissue was sent in fragments.

Histologically, the most common carcinoma is adenocarcinoma NOS $(80 \%)$, followed by papillary adenocarcinoma (4.5\%). Other uncommon variants include - intestinal type, mucinous, clear cell, signet ring, adenosquamous, squamous cell, small cell and undifferentiated carcinomas. ${ }^{22}$ In our series, 3 were papillary adenocarcinoma and two were the usual type of adenocarcinoma. Papillary carcinomas are associated with better prognosis than conventional non-papillary carcinomas. This relatively favorable prognosis has been attributed to their exophytic growth, delayed invasion into the gallbladder wall and possibly early obstructive symptoms. ${ }^{23}$

\section{CONCLUSION}

Since a variety of disease entity may come across while processing gall bladder; It should be assessed carefully. Adequate sectioning is mandatory in all cases to assess epithelial changes arising from cholelithiasis and chronic cholecystitis as it has been known to progress to dysplasia or even into malignancy.

\section{REFERENCES}

1. Adsay MV. Gallbladder, extrahepatic biliary tree and ampulla. In: Mills SE. Sternberg's diagnostic surgical pathology. 4th ed. Philadelphia: Lippincott Williams and Wilkins.;2004.pp1175-828.

2. Lester SC. Gastrointestinal, hepatobiliaryand pancreatic specimens. In: Manual of surgical pathology, Philadelphia: Churchill Livingstone; 2001.pp174-208.

3. Sharriff S, Makhija P. Liver and gallbladder. In: Sharriff S. Laboratory techniques in surgical pathology, Bangalore: Prism Books Pvt Ltd.;1999. pp70-4.

4. Rosai J. Guidelines for handling of most common and important surgical specimens. In: Rosai J. Rosai and Ackerman's surgical pathology. 9th ed. Missouri: Mosby, 2004.pp 2910-77.

5. Jessurum J. Pambuccian S. Infectious and inflammatory disorders of the gallbladder and extrahepatic biliary tract. In: Odze RD, Goddblum JR, Crawford JM. Surgical pathology of GI tract, Liver, Biliary tract and Pancreas. Philadelphia: Saunders, 2004.pp609-38.

6. Lack EE. Cholecystitis, cholelithiasis and usual infection of the gallbladder In: Pathology of Pancreas, Gallbladder, Extrahepatic biliary tract and Ampullary region. New York: Oxford university press. 2003. pp414-52.

7. Baig SJ, Biswas S, Das S, Basu K, Chattopadhyay G. Histopathological changes in gallbladder mucosa in cholelithiasis: correlation with chemical composition of gallstones. Trop Gastroenterol 2002;23:257. Crossref

8. Mohan H, Punia RPS, Dhawan SB, Ahal S, Sekhon MS. Morphological spectrum of gallstone disease in 1100 cholecystectomies in North India. Indian J Surg 2005;67:140-2.

9. Khanna R, Chansuria R, Kumar M, Shukla MS. Histological changes in gallbladder due to stone disease. Indian J Surg 2006;68 201-4.

10. Glenn F. Acute acalculous cholecystitis. Ann Surg 1979;189:458-64. PMid:443901 PMCid:PMC1397261

11. Henson DE, Albores - Saavedra J, Corle D. Carcinoma of the gallbladder. Histologic types, stage of disease, grade and survival rates. Cancer 1992;70:1493-7. Crossref

12. Mukhopadhyay S, Landas SK. Putative precursors of gallbladder dysplasia - a review of 400 routinely resected specimens. Arch pathol Lab Med 2005;129:386-90. Crossref

13. Perpetuo MDCMO, Valdivieso M, Heilbrun LK, Nelson RS, Connor T, Bodey GP. Natural history study of gallbladder cancer a review of 36 years experience at M.D. Anderson Hospital and Tumor Institute. Cancer 1978;42:330-5. Crossref

14. Albores - Saavedra J, Alcantra - Vazquez A, Cruz- ortiz H, Herrera Goepfert R. The precursor lesions of invasive gallbladder carcinoma - hyperplasia, atypical hyperplasia and carcinoma in situ. Cancer 1980;45:919-27. Crossref

15. Hansel DE, Maitra A, Argani P. Pathology of the gallbladder: A concise review. Current Diagnostic Pathology 2000;10:304-17. Crossref

16. Dix FP, Bruce IA, Krypcyzk A, Ravi S. A selective approach to histopathology of the gallbladder is justifiable. Surg J R Coll Surg Edin bIrel;2003:233-5.

17. Gupta SC, Mishra V, Singh PA, Roy A, Mishra SP, Gupta AK. Indian J Pathol Microbial 2000;43:147-54. Crossref

18. Duarte I, Llanos O, Domke H, Harz C, Vicente Valdivieso. Metaplasia and precursors lesion of gallbladder carcinoma. Cancer 1993;72:1878-84. Crossref

19. Barakat J, Dunkelberg J, Ma T. Changing patterns of gallbladder carcinoma in New Maxico. Cancer 2006;106:434-40. Crossref

20. Usha, Gupta S. Mucosal metaplasia in cholecystitis and carcinoma of the gallbladder. Ind J Pathol microbial 1990;33:92-5.

21. Shukla HS, Awasthi K, Naithani YP, Gupata SC, A clinico pathological study of gallbladder cancer. Ind J cancer 1981;13:196-201.

22. DE. Papittary carcinomas of the gallbladder - analysis of noninvasive and Albores - Saavedra J, Scoazec JC, Wittekind C, Sipre B. Carcinoma of the gallbladder and extrahepatic bite ducts. In: Hamilton SR, Aaltonen LA. Pathology and genetics of tumors of the digestive system. Lyon, France: IARC press. 2000. pp203-18.

23. Albores - Saavedra J, Tuck M, Mclaren BK, Carrick KS, Henson invasive types. Arch Pathol Lab Med 2005;129:905-9. Crossref 